\title{
Literatura y liberación en América Latina ${ }^{1}$
}

\section{Literature and liberation in Latin America ${ }^{2}$}

\section{José Revueltas ${ }^{3}$

\section{RESUMEN}

Esta disertación gira en torno a la relación literatura y sociedad. La propuesta central es que la literatura no está separada de la vida social. Incluso, la libertad de aquélla depende de la vida libre de ésta. Sólo así es posible el nacimiento de una literatura nacional con vocación uni-

${ }^{1}$ Véase (1975, julio/diciembre). Texto Crítico, I(2), pp. 3-28. Xalapa, Universidad Veracruzana. Actualizado.

2 Se reproduce la primera de dos conferencias dictadas en agosto de 1972, en Xalapa, Veracruz, en un ciclo organizado por el Centro de Investigaciones Lingüístico-Literarias, hoy Instituto de Investigaciones Lingüístico-Literarias.

${ }^{3}$ José Revueltas (Durango, México, 20 de noviembre de 1914-Ciudad de México, 14 de abril de 1976), uno de los autores más importantes de la literatura en lengua española, fue narrador, guionista de cine y ensayista político y periodístico, además de desarrollar una intensa actuación política en México, desde posiciones de izquierda. Publicó, en novela, Los muros de agua (1941), El luto bumano (1943), Los dias terrenales (1949), En algún valle de lágrimas (1957), Los motivos de Cain (1958), Los errores (1964), El apando (1969), Las cenizas (1988); en cuento, Dios en la tierra (1944), Dormir en tierra (1961), Material de los sueños (1974); en teatro, Doña Lágrimas (1941), Los muertos vivirán (1947), Israel (1947), El cuadrante de la soledad: pieza dramática (1950), Pico Pérez en la boguera (s/f), Nos esperan en abril (1956), El cuadrante de la soledad: (y otras obras teatrales) (1984); en poesía, El propósito ciego (2001); en ensayo, México: democracia bárbara (1958), Ensayo sobre un proletariado sin cabeza (1962), El conocimiento cinematográfico y sus problemas (1965), Apuntes para una semblanza de Silvestre (1966), Los procesos de México 68: tiempo de hablar (1970), México 68: juventud y revolución (1978), Cuestionamientos e intenciones (1981), Dialéctica de la conciencia (1982), México: una democracia bárbara, (y escritos acerca de Lombardo Toledano) (1983), Visión del Paricutín (y otras crónicas y reseñas) (1983), Escritos políticos: el fracaso histórico del partido comunista en México (1984), Ensayos sobre México (1985). También son de su autoría Cartas a María Teresa (1979) y Las evocaciones requeridas: memorias, diarios, correspondencias (1987). 
versal, siempre y cuando esta literatura nacional cumpla con aspectos fundamentales: tener una fisonomía propia, nacida de las particularidades históricas, expresadas éstas con un estilo singular. Las particularidades pueden buscarse en el pasado o en el presente de cada país; la singularidad, en cómo se expresan las características de la naturaleza y de la sociedad de ese país, sin desdeño de ninguna de las lenguas que hacen posible esa expresión. Muchos peligros acechan el proceso hacia una fisonomía propia, espejismos también, caídas y extravíos, pero toda literatura nacional auténtica conquistará su universalidad -no se insertará en la universalidad de otras literaturas-, dejando atrás imposiciones colonialistas, imitaciones burdas o finas, artificios y modas.

Palabras clave: Historia social; libertad de pensamiento; literatura nacional; sociología cultural; Latinoamérica.

\section{ABstract}

This dissertation spins around the relationship between literature and society. The central idea is that literature is not separated from social life, the liberty of that one depends on the free life of the latter. Only this way, the birth of a national literature with a universal vocation is possible, as long as this national literature complies with fundamental aspects: having its own physical anatomy, born from historical particularities, expressed in a singular style. These particularities can be looked for in each countries' past or present; the singularity, in how the characteristics of the nature and society of that country are expressed without disdain for any of the languages that make such expression possible. Many dangers threaten the process towards its own physical anatomy, mirages as well, falls and losses, but all authentic national literature will conquer its universality -it will not be inserted into the universality of other literatures-, leaving behind colonialist impositions, crude or fine imitations, artifices and fashions.

Key words: Social history; freedom of conscience; national literature; cultural sociology; Latin America. 
Lo primero que habría que hacer en este trabajo sería cuestionar el enunciado del mismo: Literatura y liberación en América Latina. Parecería que ese enunciado indicaría una escisión entre literatura, de una parte, y el proceso de liberación, de otra, es decir, que la literatura actuaría sobre el complejo social como una entidad ya liberada respecto de un proceso de liberación -en vías de hacerseen nuestros países. A cambio de ello, yo propondría una inversión de los términos en que está concebida la ecuación, que sería el siguiente: Enajenación y literatura en América Latina. Si no estamos, como no lo estamos, ante un fenómeno de literatura desenajenada, tenemos que insertarlo, entonces, en el proceso mismo de la situación opresiva y asfixiante en que se encuentran nuestros países, muy lejos aún de considerarse países libres, porque si consideramos la historia desde la independencia de las colonias españolas de América hasta nuestros días, el fenómeno primero que aparece en dicha historia es el de enajenación y después el fenómeno de la literatura. Posteriormente, viene ese proceso hacia una literatura nacional. Pero debemos añadir algo más: una literatura que, a su vez, también debe concebirse como literatura enajenada. Pero detengámonos un momento en el concepto de literatura enajenada. ¿En qué sentido una literatura o una expresión cultural pueden concebirse como enajenadas? ¿No es que la cultura y la literatura, por sí mismas, tienen virtudes enajenantes? ¿Por qué no considerarlas, entonces, como tales, cultura y literatura, agentes de una desenajenación del resto de la sociedad, detonadores al servicio de tal liberación? No. Se trata, precisamente, de que la tendencia hacia una literatura nacional en nuestros países aparece, desde sus comienzos, como una tendencia desenajenada. Pero también debemos penetrar en el sentido en que hablamos de enajenación respecto de literatura o de cultura en general. ¿En qué sentido, pues, podemos hablar de una tendencia enajenada de la literatura, de una literatura enajenada? En el sentido de que se trata de una expresión del lenguaje, es decir, la literatura como palabra estética donde aún no nos encontramos a nosotros mismos, ni nos 
pertenecemos en tanto que esencia universal humana realizada, objetivada por nosotros mismos como aventura propia. Todavía no nos encontramos realizados en esa literatura, es decir, ¿admitimos reconocimiento de esa esencia universal, a su vez enajenada a otro nivel superior como entidades, si se pudiera permitírseme la expresión, subenajenadas? No solamente la cultura, el arte, el pensamiento están sometidos a la enajenación de una sociedad dividida en clases, de una sociedad desgarrada por las guerras y mediatizada por los conceptos nacionales. Los países que emergen de la vida independiente a su vez emergen ya en esta situación de alienación, de enajenación. Naturalmente, existen una literatura y una cultura universales, pero ¿no constituyen ellas mismas una esencia humana realizada, objetivada, donde también nosotros, América Latina, debiéramos estar insertos? Evidentemente. Pero aquí, ante este fenómeno de una literatura universal, nuestra aventura se reduce a la expectación. No somos sus protagonistas. Hemos vivido escindidos del fenómeno universal de la cultura. Cuando, entonces, emprendemos la gran tarea, la gran aventura de desenajenar nuestra cultura, nuestra literatura y nuestras expresiones estéticas, debemos preguntarnos en qué reside el origen de esta enajenación histórica, social y de otra índole.

Para ir al fondo de la cuestión a escala universal, podemos decir que el arte, la cultura, la ciencia, la filosofía son desenajenantes porque comienzan con su propia desenajenación. Aquí parecería que hay una repetición, lo que se llama tautología, pero si nos detenemos a analizar el concepto, veremos que no se trata de una repetición. El arte, la ciencia y la filosofía, como expresiones más elevadas del pensamiento humano, desempeñan en la sociedad y en la historia un factor de libertad, un factor de desenajenación, pero ¿por qué razones? Porque al aparecer estas expresiones ya lo hacen como autodesenajenación. El arte para ser arte necesita liberarse a sí mismo de sus trabas, de sus limitaciones sociales, económicas y de la más diversa índole. Pero si decimos que se desenajena a sí mismo el arte, o la ciencia, o la filosofía, esto quiere decir que nacieron con una condición de ausencia de libertad, de ausencia de autodeterminación, de ausencia de autoregulación y de libertad por 
ellos mismos, o sea, no podría existir arte, filosofía, ciencia, etc., sin este movimiento autocrítico de su propio objeto, movimiento que, sin embargo, no le daba, en términos absolutos, la enajenación. La enajenación es un fenómeno humano mucho más profundo, que, aunque nos ofrezca momentos de libertad, a largo plazo posee o tiene una esencia enajenada, hasta que no sea posible que la sociedad dirima o disuelva sus contradicciones a nivel sumamente elevado de su desarrollo. Esto significa que hay un movimiento de enajenación-desenajenación, un movimiento que se interpenetra en sus términos. La enajenación lleva dentro de sí el contenido de su lucha contra ella misma como desenajenación. Entonces, es un proceso continuado, que va de una a otra parte de la ecuación a través de las diferentes totalidades que aparezcan en el contexto, ya como situación, ya como proyecto, es decir, si nosotros tomamos una determinada totalidad, el hombre natural, veremos cómo éste, el hombre naturaleza, evoluciona y se desarrolla dentro de un contexto de sucesivas enajenaciones y desenajenaciones. Su primera lucha contra la naturaleza para modificarla y para obtener el sustento es una lucha enajenante, pero al mismo tiempo es una lucha desenajenante, puesto que lo provee de los utensilios mediante los cuales puede independizarse de la naturaleza hasta el momento en que ya fabrica herramientas. Y la modificación de la naturaleza se multiplica, es decir, ya no es la modificación directa de la mano hacia el objeto, sino que es de la mano mediada por el instrumento que multiplica el valor y el esfuerzo de la mano. Lo mismo ocurre si tomamos al hombre como totalidad dentro del contexto de las diferencias de clase: entonces, el hombre está enajenado a la clase más poderosa, pero se desenajena mediante las revoluciones o la lucha contra la opresión de la clase dominante. Lo mismo sucede si tomamos al hombre en su totalidad en cuanto sociedad capitalista: el hombre dentro de la sociedad capitalista produce plusvalía, produce mercancías y esto lo enajena al dueño de los medios de producción, pero al mismo tiempo que produce mercancías, hace o desempeña el papel de proletario que niega, con su presencia y con su actividad, el papel de todas las demás clases de la sociedad y se desenajena en tanto que es clase explotada por el capitalismo. 
De igual modo, si tomamos la totalidad del hombre dentro de la burocracia socialista: hemos visto que en los años de dominación de la burocracia socialista en los diversos países de socialismo del estado -Unión Soviética, Polonia, etc.- ha dado muestras de desenajenación, ya sea mediante movimientos de huelga, protestas, etc., o, si no, en la expresión de sus hombres más conscientes: sabios, intelectuales, escritores, que aciertan a protestar, finalmente, en el aspecto que nos atañe, en el mundo contemporáneo. La totalidad del hombre podríamos tomarla desde el punto de vista de la referencia de la energía nuclear y de las bombas atómicas. Vivimos, entonces, el mundo contemporáneo. En una sociedad atómica, donde el hombre adquiere sustancialmente y en esencia una nueva naturaleza, enajenada a la realidad de estas fuerzas descubiertas y manejadas por el ingenio humano y destinadas a la destrucción del propio género humano. Para comprender lo que sigue, quisiera hacer un breve paréntesis respecto del uso de los términos: a fin de cuentas, las palabras no son sino herramientas y necesita uno manejarlas en tanto que tales herramientas para develar la realidad, para penetrarla y darse cuenta de las relaciones internas que la unen.

Primero el concepto de totalidad. Tomamos el concepto de totalidad como el área de conocimiento o de transformación de la cosa que se remite a una referencia unificante, de la cual adquiere sus valores significativos. Si abarcamos un gran campo, un área inmensa o infinita del conocimiento, no tendremos conocimiento alguno. Necesitamos sustraer a la infinitud del conocimiento áreas determinadas del conocer y del transformar para poder entender los procesos internos que las informan. Eso arroja un conocimiento relativo de la cosa. Pero por acumulación de conocimientos relativos, llegamos al conocimiento completo y al conocimiento absoluto en condiciones específicas, es decir, no al absoluto en total, pero sí a cierto conocimiento absoluto. Las leyes de la gravedad, por ejemplo, han llegado a ser un conocimiento absoluto hasta cierto punto. Con esto quiero decir que la verdad absoluta no es obtenible, pero sí, en cambio, la verdad concreta, mediante áreas del conocimiento. Estas áreas del conocimiento se obtienen metodológicamente mediante 
la sustracción a un conjunto de realidades de ciertos segmentos de esa realidad, como áreas del conocimiento para su penetración intelectiva. Por ejemplo, volviendo a citar al hombre como objeto del conocimiento, el hombre biológico, el hombre socio-histórico, el hombre sociológico, etc., si abarcamos la totalidad del hombre o la totalidad absoluta del hombre, tendremos todos sus segmentos del conocimiento, que acaso, de no tomarlos en cuenta, nos impedirían un conocimiento cabal. Tenemos, entonces, que segmentar, desde el punto de vista puramente metodológico, al hombre como ser biológico, al hombre como ser social, al hombre como ser sociológico, para explicar estas disciplinas. A esta segmentación, a esta selección de las áreas de conocimiento, es a lo que llamamos totalidad. Para evitar la caída sumamente riesgosa y despistante de considerar verdades absolutas o absolutos de alguna otra especie, explico enseguida el término situación.

Debemos entender situación, y voy a poner un ejemplo muy común, como aquella actividad que se resume en estar colocado en un determinado número de relaciones con respecto de un objeto. Se dice que un actor está en situación cuando asume todas las relaciones del drama que tiene que representar. Un actor se puede excusar con el director de teatro diciéndole: "No me encuentro en situación”, es decir, ha roto su relación interna como actor respecto de un grupo de circunstancias determinadas. Entonces, intentando definir condensadamente la voz situación podríamos decir que es la relación de relaciones del objeto en un punto dado del desarrollo de sus tendencias hacia esto o aquello. Repito el ejemplo: un actor dramático reproduce la situación de un suicida, entonces, inclusive fuera del texto dramático, el actor ha de acumular todo aquello que podría hacerlo un suicida en la vida real, fuera del contexto de lo que tiene que decir en escena, puesto que aquello que debe decir en escena acaso le sea indiferente, pero no le son indiferentes las relaciones que en su propia vida puede encontrar para un suicidio. Entonces, el efecto sería realmente la transmisión de la emoción del suicidio. Un ejemplo más: la relación de relaciones entre el agua y la temperatura coloca al agua en situación de ser hielo o vapor: según la temperatura que se le aplique, o la temperatura que no se 
le aplique, seguirá siendo un agua pasiva, sin movimiento, fuera de las normas de una temperatura elevada o de una temperatura descendente: será siempre $\mathrm{H}_{2} \mathrm{O}$. Pero aplicada a la temperatura, el agua se podrá convertir en hielo o en vapor. Esta es la relación de relaciones que determina la situación del agua. Los ejemplos sirven para que se advierta que no se trata de la simple acepción corriente del término situación, sino a qué conjunto de circunstancias entrelazadas que determinan la posición de un sujeto por cuanto a las relaciones objetivas y también sumergidas en que actúa sobre el objeto o el objeto actúa sobre él.

Analicemos, por último, el término proyecto. Proyecto significa la actitud -palabra que proviene de acto, de hacer-, la actitud que sustenta su posibilidad en la tendencia interna del objeto. Aquí debemos hacer más esclarecimientos, para no confundirnos. Se trata de la actitud que sustenta su posibilidad en la tendencia interna o externa del objeto. Yo opero una actitud sobre el automóvil que me va a atropellar o que no me va a atropellar. Pero la actitud es o someterme a las señales de tránsito o atravesar la calle corriendo. Entonces, este es mi proyecto. Yo abrigo un proyecto en escala menor al atravesar la calle. No me aventuro a atravesar la calle si no sé la tendencia del objeto. En este caso, la tendencia del objeto, si tiene luz verde, es pasar sin consideración para el peatón, porque no puede frenar en un momento dado dentro de un terreno limitado. Entonces, yo adivino, es decir, estoy viendo la tendencia del objeto por cuanto a mi relación con él, en el sentido de que si yo falto a los reglamentos de tránsito, corro más riesgos de que se me atropelle. A cambio de no correr ese riesgo, observo los reglamentos.

Tomemos ahora una situación: América Latina. Considerémosla como una situación, como una totalidad significativa, por cuanto a la literatura, factor que, a su vez, desempeñará el papel de referencia unificante respecto de dicha totalidad. Tenemos, pues, nuestro continente y nuestros países como una situación equis, una situación que vamos a determinar apelando a una tendencia unificante de toda su variedad, que se condensaría en el concepto o los elementos que integran el concepto: literatura o cultura. Esta referencia, la cultura y la literatura, unifica la variedad del continen- 
te, de nuestros países respecto de una situación determinada, una situación concreta por cuanto al fenómeno del desarrollo literario en general. Pero quien dice literatura dice algo también más elevado y con compuestos menos elementales que lo que pudiera ser la palabra literatura. Si no la conceptuamos a un nivel superior, ¿por qué hay literatura francesa, literatura americana, literatura latinoamericana, ecuatoriana, etc.? Al decir literatura, estamos, pues, diciendo una cosa más: estamos refiriéndonos a un complejo cultural en su conjunto, o sea, a un conjunto de relaciones de producción científicas, estéticas, filosóficas, en resumen, a una superestructura. Pero no debemos dejarnos llevar por la facilidad que implica el concepto de superestructura en lo que se refiere a las superestructuras culturales, jurídicas, etc. Según el marxismo vulgar, están predeterminadas y condicionadas causalmente por las infraestructuras económicas. No. En el caso de la superestructura cultural, estética y jurídica, inclusive, de una sociedad, se trata de una estructura o superestructura diacrónica respecto de las bases y factores económicos, es decir, que no coincide con esas bases y relaciones económicas; que es todavía superior a esas bases y relaciones económicas, y superior, incluso, a la sociedad en la que tuvo su origen. Esto no significa que las expresiones inmediatas de la cultura -como, por ejemplo, el libro que aparece, la opinión que se vierte, el poema de circunstancias, que puede también tener un contenido mucho mayor que las circunstancias mismas, se hallen desvinculadas de la economía de la sociedad, pero vinculación no quiere decir determinación. Las formas superiores de la cultura no son determinadas ni por la historia, ni por la sociedad, ni por la economía. Tenemos el ejemplo del lenguaje, del lenguaje hablado y el escrito. El lenguaje es una expresión universal de la comunicación entre los hombres y no tiene nada que ver, salvo como lenguaje dialectal o lenguaje coloquial, con las relaciones de producción. El lenguaje no cambia de una sociedad a otra, ni de un grupo de sociedades a otro. El mundo, la humanidad, ha atravesado la esclavitud, el socialismo, el capitalismo, y su lenguaje sigue siendo una expresión constante, en la cual se introducirán términos nuevos por cuanto a la técnica de la relación del trabajo, pero sustancialmente no sufrirá ningún 
cambio. Estas superestructuras culturales no están determinadas ni por la sociedad, ni por la economía, ni por la historia, aunque arranquen de su seno, lo cual quiere decir que son formas metahistóricas, más allá de la historia, es decir, desenajenadas respecto de su inmediatez ideológica, política y socio-económica dada.

Quiero distinguir ahora entre inmediatez y constancia de las cosas. Pongamos un ejemplo. El concierto Emperador de Beethoven se llama así porque Beethoven lo dedicó a Bonaparte; y cuando Bonaparte asumió una actitud contraria a las ideas de Beethoven, éste le quitó la dedicatoria. Sometió su obra artística a una circunstancia histórica inmediata: el papel que Napoleón desempeñaba en un momento determinado de la historia. Bastó quitarle eso, pero la obra no fue dañada, es decir, la inmediatez a que estuvo sometido el concierto Emperador se anula con un acto que no afecta su contenido ni tampoco su forma. Al mismo tiempo, vimos cómo en la Segunda Guerra Mundial los primeros acordes de la Quinta sinfonía de Beethoven se usaban como rúbrica musical de los aliados para transmitir los partes de guerra en la lucha contra Hitler. Termina la guerra, pero queda en pie la Quinta sinfonía. Las relaciones inmediatas de la política y de la ideología no determinan el arte ni lo apartan de su esencia, aunque pueden ser utilizados por la ideología y la política. El arte y sus formas permanecen en una situación diacrónica respecto de la sociedad, la economía y la historia. Metodológicamente, estamos haciendo aquí relación de relaciones, dentro de la que podemos insertar a la América Latina como totalidad significativa, por cuanto la colocamos en situación, o sea, en la situación que le corresponde como situación cultural, que es lo que nos interesa en este caso. El problema fundamental reside en lo siguiente: la tardía emancipación política de las colonias españolas de América condicionó el increíble retraso con que sus pueblos comparecen ante la situación cultural del mundo en el siglo XIX. La dominación española fue un lapso enorme para el desarrollo de los pueblos, un lapso de más de tres siglos en que las colonias españolas de la América estuvieron condenadas a un aislamiento cultural y a un hermetismo que les impedía la relación con los países más avanzados de la tierra. La raíz de esto hay que 
buscarla en el movimiento de Contrarreforma que encabeza España en el siglo XVI, cuando sobreviene la gran revolución política, ideológica y cultural en Europa: esta grande y profunda revolución encuentra su oposición más empecinada y violenta en España, donde Ignacio de Loyola funda la Compañía de Jesús como un ejército militante para combatir por los fueros de la religión, de la Inquisición y del dogma. De esta suerte, la Contrarreforma se traslada a las colonias de América sin enemigo al frente, expresándose en una forma mucho más violenta, virulenta, intolerante de la que tenía en la Europa del siglo XVI y subsiguiente. Se erige en las colonias españolas de América la Inquisición; y en el terreno del conocimiento, priva la escolástica; en el de la política, el hermetismo más cerrado; y en el de la cultura, un total ensimismamiento. No se permite la circulación de libros extranjeros, de libros que no sean en español o en latín autorizados por el Index; de tal suerte que los países de América se retrasan absolutamente respecto del proceso revolucionario que tiene lugar en Europa y que fue el que justamente abrió la perspectiva para un desarrollo ulterior de estos países. Porque a veces ocurre preguntarnos por qué el desarrollo no fue el mismo en América del norte, en la América sajona, y en la América española. Precisamente porque aquellos pobladores de la América del norte, de la América sajona, debían ejercer la libertad que en Inglaterra les negaba Jorge III. Y esto facilitó el desarrollo de las fuerzas productivas y el desarrollo de las conciencias. No así en nuestra América, donde la Contrarreforma sentó sus reales de una manera definitiva. De aquí que las naciones de la América Latina nazcan en el siglo XIX sin cultura propia, pero a la búsqueda afanosa de esa cultura, por todos los caminos. La cultura que se les ha dado hasta entonces es universal, ciertamente, pero es falsamente ecuménica; en suma, enajenada. Aunque no hayamos tenido acceso a la cultura universal, esta cultura se nos ha arrebatado, porque como parte de la humanidad nos correspondía. Nos correspondía ese avance global en compañía de todo el resto de la humanidad. Así que comparecemos a la historia, a la historia independiente, inválidos, mancos y faltos de cultura. De aquí que el proyecto de la situación cultural de la América Latina sea la reapropiación de la 
cultura. Su desenajenación se plantea, entonces, como una relación doble, a la vez positiva y negativa, respecto del objeto. ¿Permitirán ustedes una pequeña digresión en torno de estos términos, para que podamos seguir avanzando en la comprensión del contexto?

Repito, entonces, que el camino hacia la desenajenación de la cultura, hacia su reapropiación por los pueblos de América, reviste una doble relación, que es a la vez positiva y negativa. Es positiva por cuanto niega la negación, es decir, niega aquello que le es adverso. Y es negativa por cuanto lo afirma. Vamos a poner un ejemplo. Tomemos un status social dado, cualquiera que éste sea. El gobierno dentro de ese status es positivo respecto de sí mismo, en cuanto reprime la oposición revolucionaria. Es positivo porque niega lo que lo niega a él mismo. Luego, en consecuencia, la acción revolucionaria es negativa por cuanto afirma la negación del status; está en contra de aquel establecimiento. Al negar la negación del status, se vuelve positiva, y se vuelve positiva mediante la negación de su propia negación. Si un grupo determinado como posición revolucionaria niega ya su razón de ser, acepta ya la negación de su negación, será únicamente por dos causas: una porque el status se haya cambiado, se haya subvertido por un status nuevo, o porque esta posición, esta acción revolucionaria, ha claudicado, se ha identificado con el régimen y se ha sumado a él. Es el caso, por ejemplo, aunque parezca poco oportuno, de los nuevos partidos que intentan crearse: partidos revolucionarios o un partido revolucionario determinado, que no niega el status, sino que trata simplemente de modificar sus consecuencias menos trascendentes, es decir, esta acción es positiva hacia el régimen, hacia el status imperante. Ahora bien, traslademos esos conceptos a la situación de la literatura en la América Latina en su totalidad concreta y significante, en la relación de relaciones con su objeto, o sea, la reapropiación de la cultura universal a la cual no tuvo acceso. Tenemos entonces, en el cambio de esa reapropiación de la cultura, tres aspectos fundamentales. El primero es que en esa búsqueda de la reapropiación de la cultura trata uno de encontrar su fisonomía propia, su diferencia respecto de otra expresión cultural, su particularidad, lo nacional de esas expresiones y su singularidad, el estilo de esas propias expresiones. 
Naturalmente que no de una manera alícuota, es decir, que marchen los tres factores al mismo tiempo, como los caballos de Roma tirando de un vehículo en las carreras olímpicas, o lo que fuere, sino que una luz pone el acento en la necesidad de una fisonomía propia, otras sobre la particularidad y otras más en la singularidad. Pero recordemos muy bien el afán, la búsqueda de una expresión cultural propia. América Latina se traza tres requisitos o tres metas por alcanzar. Una fisonomía literaria propia, es decir, su diferencia respecto de otros países, su particularidad, esto es, lo nacional en esa literatura, y su singularidad, el estilo con que se exprese así. En la literatura en nuestro continente, a partir de la Independencia -no quiero referirme a otros periodos porque deseo ligar dentro del tema de la liberación del continente las expresiones culturales; y si nos vamos a un pasado más remoto, sería ya un asunto de otra metodología y de otra exposición muy distinta- el proceso de la búsqueda de estas tres significaciones en la totalidad de la relación de relaciones, literatura e historia, tiene diferentes expresiones que vamos a enumerar.

Primero la búsqueda de lo nacional, es decir, de la particularidad literaria en el pasado histórico. Es aquí cuando tenemos algunas expresiones literarias que se sustentan en el prehispanismo. A este respecto, habría que citar a Ireneo Paz -por cierto, bisabuelo de nuestro amigo Octavio Paz-, quien produce novelas en que su temática va más allá de la conquista española; sus personajes son nahuas, príncipes aztecas, etc., novelas que podríamos clasificar, en cierto sentido, como de tipo arqueológico. Otro aspecto de la búsqueda nacional en el pasado histórico lo tenemos en aquella temática que se orienta hacia la vida colonial de los tres siglos de dominación. Aquí cabría mencionar, entre otros, a Riva Palacio, con Monja casada, virgen y mártir y Martín Garatuza; a Francisco Monterde, autor de Moctezuma, el de la silla de oro; y a Jorge de Godoy, con una serie de cuentos que transcurren en el pasado colonial mexicano. Hay aquí, evidentemente, una búsqueda de lo nacional, sin contar, por ejemplo, los Episodios nacionales, de Salado Álvarez, que no son sino una reversión de los modelos europeos de literatura, particularmente de la literatura española al acontecimiento 
mexicano. No es un accidente que Salado Álvarez haya transcrito el título de la obra cumbre de Pérez Galdós, Episodios nacionales, hacia la realidad mexicana del siglo xIx, a partir de la Revolución de Ayutla, la Reforma y el Imperio.

Otro aspecto de esta búsqueda se expresa en lo nacional que quiere realizarse en la inspiración del presente histórico. En este caso, se encuentran los novelistas de la Reforma en México: Manuel Payno con Los bandidos de Río Frío, Juan A. Mateos con su colección, su trilogía sobre la Guerra de Tres Años, la Reforma y el Imperio, e Ignacio Manuel Altamirano. Luego, un ejemplo notable, cómo hay una retrocaptación de la lucha contra el esclavismo, en la novela romántica María, de Jorge Isaacs. Todo aquel aspecto de María que se refiere a la lucha contra el esclavismo no es sino una retrocaptación de una situación social presente, a la sazón, en su país, respecto del peligro de una repetición de la esclavitud de los negros africanos que fueron traídos a América. En seguida, tendríamos otra categoría de esta búsqueda en lo nacional por el costumbrismo y la tradición. Aquí hay ejemplos patentes: Fernández de Lizardi en El Periquillo Sarniento, Ricardo Palma en Las tradiciones peruanas.

Al ver que estas formas no permitían la inserción o eran insuficientes para permitir la inserción de nuestra cultura a escala universal, sobreviene, en cierto sentido, un cambio de orientación: la búsqueda de la fisonomía, de la diferencia, a través del encuentro de una fisonomía propia. Aquí podríamos explicar lo que en lógica se conoce como definición por género próximo y diferencia específica. El género próximo sería la novela y la diferencia específica aquello que distinguiera a la novela mexicana o americana, en general, de otras expresiones de tipo europeo. Sin embargo, el saldo no es el encuentro de una diferencia específica; un género próximo sí, mas no una diferencia específica. Así que no se obtiene la fisonomía propia de tipo universal, aunque represente, a determinada escala, una fisonomía propia dentro de un perímetro nacional, pero, a su vez, limitado. Y limitado inclusive por el tiempo. Es posible que El Periquillo Sarniento ya no nos diga nada, aunque fue en su tiempo una buena crítica de las costumbres y una ad- 
quisición de una fisonomía propia poco duradera. Ya El Periquillo Sarniento no informa nuestro yo nacional de modo tan cabal como se lo propuso su autor.

Y en seguida de la búsqueda de la fisonomía propia, de la diferencia en virtud de la fisonomía propia, la búsqueda de esta diferencia por la singularidad, el estilo. Esta gama es mucho más rica que las anteriores y nos presenta, en términos esquemáticos, el siguiente panorama. Vuelvo a repetir, se trata de la búsqueda literaria de una fisonomía propia a través de la diferencia y la singularidad, entendiendo por singularidad el estilo de la expresión. En este grupo tendríamos el siguiente panorama.

a) El clima y el paisaje, la naturaleza aplastante. José Eustasio Rivera, en La vorágine; Rómulo Gallegos, en Canaima. Respecto de este último autor, habría que detenernos en una consideración interesante: en Canaima, Rómulo Gallegos expresa claramente esta lucha contra el paisaje, esta lucha contra la naturaleza, que a veces arroja la victoria o a veces arroja la derrota a los protagonistas. Doña Bárbara se aparta de Canaima; pero ¿por qué se aparta de Canaima? Porque en Doña Bárbara registra Gallegos otra etapa, anterior a la precedente a la que informa Canaima. Doña Bárbara es la aparición de un nuevo tipo de relaciones de producción; Doña Bárbara representa socialmente la introducción de nuevas formas de producción en el campo, la hacienda más moderna, etc., pero que se inserta -esta relación y producción, que están imbricadas- dentro de las viejas estructuras ideológicas. Doña Bárbara no renuncia a invocar las prácticas de hechicería ni al famoso amigo, que se supone es una especie de Satanás, etc. Todos vemos aquí esta paradoja social, que, además, se da en la vida real de nuestros países, en que la introducción de relaciones capitalistas de producción en el campo no implica, sin embargo, una desenajenación respecto de las supercherías y fetichismos precedentes. Esto sería el grupo a), en que la búsqueda de una fisonomía propia y de una singularidad en el estilo se dan a partir del clima y del paisaje y del carácter aplastante de la naturaleza. En La vorágine, el personaje termina su destino con un epitafio del autor: "Y lo devoró la selva." 
b) Indigenismo, folclor, tribalismo literario, ensimismamiento del lenguaje. Aquí notamos, dentro de la búsqueda de lo nacional, un retroceso, un salto hacia atrás, creyendo que lo nacional puede radicar en un idioma no universal, en locuciones no universales del idioma, como la novela Huasipungo, de Jorge Icaza, que necesita un vocabulario especial para entenderse, por los giros locales e indígenas insertos en ella. O el caso de José María Arguedas, en su libro Todas las sangres, una novela que, en una quinta parte, está escrita en quechua.

c) El cosmopolitismo como falsa conciencia de lo universal. Entramos ya de lleno en ciertos aspectos de la novela moderna. Lo extranjero aparece en esta novela moderna o se desempeña como un simple back projection, teniendo al fondo un escenario artificioso, para satisfacer las subconciencias colonizadas. Del mismo modo, sólo que a la inversa, los escritores extranjeros satisfacen la conciencia colonizante de su público con personajes y situaciones de su país de origen, que se mueven sobre un back projection exótico. Es el caso de Graham Greene, D. H. Lawrence, Aldous Huxley, tratando de universalizar sus expresiones literarias; y para ello, estos autores colocan la acción y el desempeño de sus personajes en ambientes cosmopolitas extranjeros. Teniendo, pues, como telón de fondo la Tour Eiffel, hemos creído ya que conquistamos la universalidad, porque la novela se desarrolla en París y no en Bogotá, o Caracas, o Tegucigalpa. Es el movimiento inverso, que se produce por imitación respecto de los grandes novelistas de nuestro tiempo. Yo citaba los nombres de D. H. Lawrence, de Graham Greene, de Aldous Huxley, particularmente los ingleses. Las novelas de ambiente extranjero de estos ingleses, así se desarrollen en Tahití o en Italia, se desarrollan entre personajes ingleses, con convenciones inglesas, aunque nos den un mensaje universal. Ellos, como universales, entienden subconscientemente la universalidad como colonización. Y hablo de un subconsciente histórico y no de una conciencia determinada en esa dirección. Adolecen de este cosmopolitismo como falsa conciencia de lo universal escritores de tan alto mérito como Julio Cortázar o Carlos Fuentes, este último aun en sus obras más mexicanas. 
Ahora bien, todavía tenemos una nueva categoría, d) la asincronía y la desincronía como recurso literario para obtener una fisonomía propia. Y al mismo tiempo, otra corriente más: e) lo absoluto irreal en la búsqueda de una expresión original. En el caso de la asincronía y desincronía, tendríamos como ejemplo Cien años de soledad. El ejemplo más claro: la invención del hielo por un Buendía en Cien años de soledad, que es una desincronía respecto del nivel de desarrollo del mundo, porque en unas obras determinadas el descubrimiento del hielo o la importación de un bloque de hielo puede parecer mágico o increíble a los protagonistas y a los habitantes de aquel pueblo. Esta desincronía con el nivel de desarrollo mundial es sorprendente y ha debido tener un buen margen de desarrollo poético. En este caso de asincronía o desincronía, cito a Cien años de soledad como un ejemplo clásico; y cito como en lo absoluto irreal el caso de $P$ edro Páramo, de nuestro compatriota Juan Rulfo. Estas expresiones, estos recursos de asincronía y desincronía y de absoluto irreal, sin embargo, parecen no salir de su fórmula irrepetible y, por lo tanto, de continuar en uso, amenazan con caer, como los juegos de mano, en la monotonía de truco descubierto. Ya descubierto el truco de esas formas de expresión, el truco es irrepetible, como cuando hemos descubierto un juego de manos en que desaparecen las barajas o aparece una paloma salida de la mano del mago. Las repeticiones de ese truco ya no sorprenden a nadie; y por otro lado, agota sus propios recursos, por lo cual yo considero que, en este caso, estos escritores incurren en una fórmula hecha y no vista hasta la aparición de sus novelas, pero que, por el mismo carácter que tiene de artificio, corre el riesgo de caer en la monotonía y en la falta de sorpresa, en una literatura plana, sin absolutamente ningún porvenir.

f) Finalmente, tendríamos lo universal real o lo real universal. Dentro de esta categoría, yo citaría a Alejo Carpentier, a Juan Carlos Onetti y, en menor grado, a Ernesto Sábato y a Manuel Rojas. Aquí ya hay un intento sumamente serio y logrado, además, de insertarse en lo universal a partir de lo nacional. El siglo de las luces y El reino de este mundo, de Carpentier, son narraciones, relatos novelísticos y estructuras asentadas en una tierra de crecimiento inconmensurable, profunda y fértil, que es lo nacional tomado como historia real, no 
como historia pasajera ni circunstancial: es la historia de las islas del Caribe, de sus problemas internacionales, es decir, de aquellos problemas que conectaban, por ejemplo, la situación de algunas islas del Caribe con la Revolución Francesa, y que le confieren una universalidad de primera magnitud al trabajo de Carpentier. Lo mismo en el caso de Juan Carlos Onetti. Habría que señalar aquí una circunstancia que quizá tenga significación: el ambiente de las novelas de Juan Carlos Onetti está un tanto relacionado con la situación geográfica de sus motivaciones: puertos, astilleros, etc., relaciones geográficas que anuncian, en sí mismas, un deseo de comunicación, un deseo de partir, un deseo de ir hacia algo, hacia un fin determinado. Ernesto Sábato logra, en Sobre héroes y tumbas, una comunicación histórica universal. Es que lo propio y lo específico de un Buenos Aires de cierta época se conectan con un proceso histórico universal de liberación.

Nos preguntaremos a dónde va, pues, nuestra literatura y cuál es el campo de su expresión desenajenada. Esto no podemos desvincularlo del fenómeno literatura y revolución en español. La revolución en español ha comenzado en Cuba, siguió luego en Chile, seguirá en América Latina. Esta revolución en español nos dará la perspectiva de una verdadera cultura. Comenzó con la guerra de España en contra de la invasión fascista de Hitler y Mussolini y en contra de los generales traidores y seguirá como una bandera de desenajenación cultural en todos los países de nuestra América Latina. 